\title{
Verification Stability of Anion-Exchange Membrane with Surface Modification with Application in Electrodialysis Process
}

\author{
Lucie Zarybnicka ${ }^{1,2^{*}}$, Eliska Stranska ${ }^{3}$ \\ 1 VSPJ, Tolsteho 16, 58601 Jihlava, Czech Republic \\ ${ }^{2}$ Institute of Chemistry and Technology of Macromolecular Materials, Faculty of Chemical Technology, University of Pardubice, \\ Studentska 573, 53210 Pardubice, Czech Republic \\ ${ }^{3}$ MemBrain s.r.o., Pod Vinici 87, 47127 Straz pod Ralskem, Czech Republic \\ * Corresponding author, email: Zarybnicka.L@email.cz
}

Received: 28 September 2017, Accepted: 23 January 2018, Published online: 16 February 2018

\begin{abstract}
The present work deals with verification stability of the prepared anion-exchange membrane with surface modification in the time. The surface modification of a commercial ultrafiltration poly(ethersulfone) membrane was carried out graft polymerization. Poly(styreneco-divinylbenzene-co-4-vinylbenzylchloride) surface layer was covalently attached onto commercial ultrafiltration support layer. The membrane was tested from the point of view of water content, ion-exchange capacity, specific resistance, permselectivity, FT-IR spectroscopy and SEM analysis. The tested characteristics (IEC, permselectivity, resistances, structure) of the prepared membrane were same after one year from preparation. The prepared membranes can find use in electrodialysis processes.
\end{abstract}

Keywords

anion-exchange membrane, surface modification, graft polymerization, stability verification

\section{Introduction}

Nowadays there is an increasing use of differently modified membranes. Their use is being expanded in the ever-growing industry for separation and purification processes, biotechnology, nanotechnology and membrane power plants. Ion-exchange membranes are membranes that carry dissolved ions through a conductive polymeric membrane [1-2]. These membranes find application of desalination and chemical regeneration, moving ions from one solution to another with a small passage of water [3]. Ion-exchange membranes used in electrodialysis and EDR include seawater desalination, industrial waste water treatment in highly soft waters, food and beverage production, and other industrial waste water [4-6]. Ion-exchange membranes based on commercially available polymers can be prepared in several ways [7], a semi-interpenetrating polymer networks [8] or organic-inorganic hybrid membranes [9-12].

PES membrane is one of the highly developed materials used by the separation processes. It was used, for example, to prepare a $\mathrm{TiO}_{2}$ microporous membrane [13] for the preparation of a nanofiltration membrane containing
GO (graphene oxide) [14]. PES membranes are used in electrochemical processes [15-18]. One of the important parameters of ion-exchange membranes is their stability [19-20]. This problem is a very important parameter for industrial use.

The present work deals with the verification of selected properties of modified PES membranes [21] over time. We managed to prepare a modified PES membrane, which was characterized by selected methods. The modification consisted of multi-step preparation - graft polymerization, extraction of unreacted monomer units, amination with trimethylamine followed by treatment with $\mathrm{HCl}$ solution and $\mathrm{NaOH}$. Water absorption, IEC, specific resistance and permselectivity were determined for the prepared membranes. Morphology was characterized by FT-IR spectroscopy and SEM analysis. The membranes can be tested for stability at rest or during using in practice. It's necessary to know what stability is in time before using and this was also our study goal. We have tested the prepared membrane for 1.5 year from preparation. 


\section{Experimental part}

\subsection{Materials and chemicals}

PES ultrafiltration membrane (type $5 \mathrm{kDa}$ MT, Table 1, molecular weight cut-off of $5 \mathrm{kDa}$ ) (Synder Filtration, Inc. USA), divinylbenzene (DVB) (Sigma-Aldrich, Prague, Czech Republic, purity 80\%), styrene (St) (SigmaAldrich, Prague, Czech Republic, purity 99.9\%), 4-vinylbenzyl chloride (VBC) (Sigma-Aldrich, Prague, Czech Republic, purity 90\%), benzoyl peroxide (BP) (SigmaAldrich, Prague, Czech Republic, 75\% remainder water), tetrahydrofurane (THF) (Penta Chemicals, Chrudim, Czech Republic, purity min. 99\%), trimethylamine (TMA) (Sigma-Aldrich, Prague, Czech Republic, 45 wt.\% in H2O), methanol (Penta Chemicals, Chrudim, Czech Republic, purity min. 99\%).

\subsection{Surface modification}

The surface modification of PES membrane consisted in grafting a polymeric surface layer onto a commercial PES membrane support layer [21]. The preparation of the modified PES membrane was multi-step (Fig. 1). In the first step, the PES membrane $(1.5 \times 1.5 \mathrm{~cm})$ was cleaned overnight using distilled water and methanol at the laboratory temperature under continuous stirring. The membrane was immersed in the mixture of monomers (32.5 wt.\% St, 16.2 wt.\% DVB and 48.7 wt.\% VBC) that were copolymerized in the presence of $2.6 \mathrm{wt} . \% \mathrm{BP}$ initiator. The reaction proceeded at $80{ }^{\circ} \mathrm{C}$ for $5 \mathrm{~h}$. After the PES layer was formed, the membrane was tailored by Soxhlet extraction using tetrahydrofurane. The extraction was terminated after 72 hours. The amination of the surface modified PES

\begin{tabular}{lc}
\multicolumn{2}{l}{ Table 1 Specification of PES ultrafiltration membrane. } \\
\hline Parameter & Value \\
\hline pH range & $1-11$ \\
Flux (GFD)/psi & $120147 / 50$ \\
Pore size/MWCO & $5000 \mathrm{Da}$ \\
Max. Operation $\left({ }^{\circ} \mathrm{C}\right)$ & 50 \\
Max. Inlet Pressure & $8 \mathrm{bar}$ \\
Min. Outlet Pressure & $0.7 \mathrm{bar}$ \\
\hline
\end{tabular}

membrane was performed for introducing anion-exchange functionalities by using $45 \mathrm{wt} . \%$ TMA in $\mathrm{H}_{2} \mathrm{O}$. The amination proceeded at room temperature for $24 \mathrm{~h}$, followed by conditioning in $1 \mathrm{M} \mathrm{NaOH}$ for 24 hours, washing with distilled later and subsequent conditioning in $1 \mathrm{M} \mathrm{HCl}$.

\subsection{Membrane characterization}

\subsubsection{Morphological studies}

The surface morphologies of prepared membrane were examined by scanning electron microscope QUANTA FEG 450 using ESEM mode (Thermo Scientific ${ }^{\mathrm{TM}}$, Waltham, USA). The samples were chrome plating.

\subsubsection{FT-IR spectroscopy}

The membranes were characterized by infrared spectroscopy on a modular instrument IS50 FT-IR (Thermo Scientific ${ }^{\mathrm{TM}}$, Waltham, USA). The reflective technology ATR (IS50 ATR) equipped with diamond crystal, KBr beam splitter, InGaAs detector $2.6 \mu \mathrm{m}$, IR radiation source, $\mathrm{HeNe}$ reference laser and linear scan Vectra ${ }^{\mathrm{TM}}$ interferometer was used. The resolution was $2 \mathrm{~cm}^{-1}$ and the spectrum was integrated from 64 scans. The measurements were

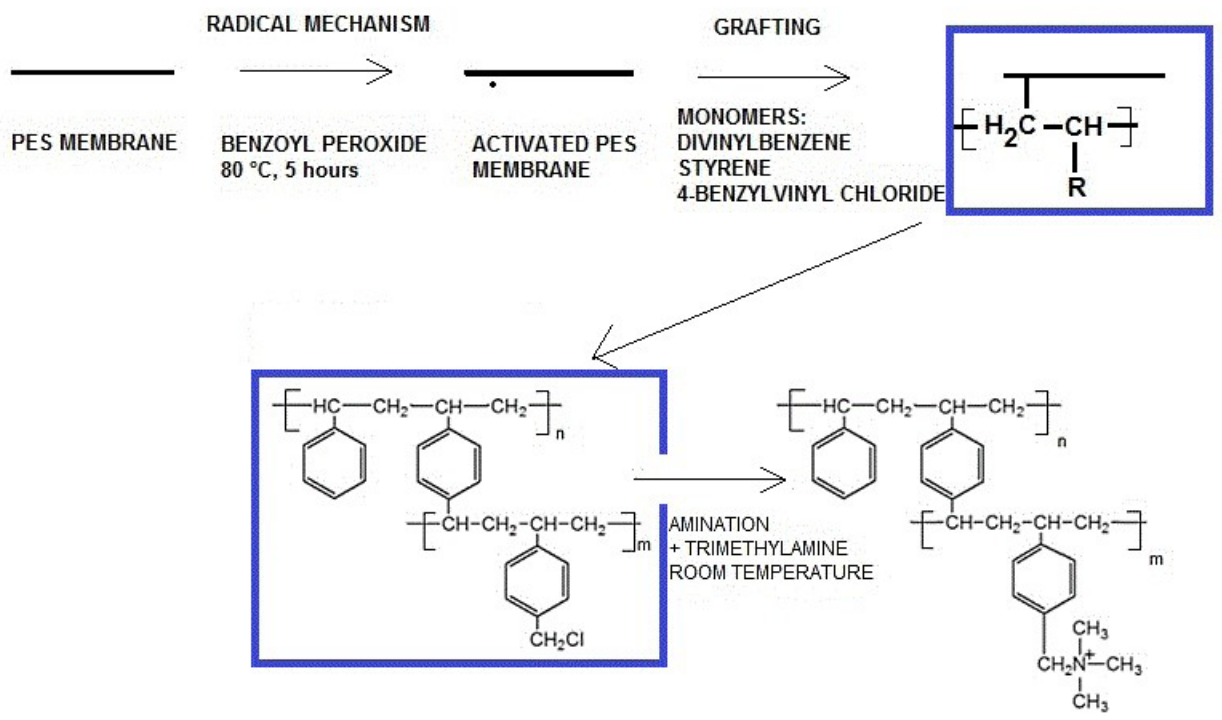

Fig. 1 Process of the prepared poly(styrene-co-divinylbenzene-co-4-vinylbenzylchloride) surface layer. 
performed in the range from $4000 \mathrm{~cm}^{-1}$ to $400 \mathrm{~cm}^{-1}$. The resulting spectra were processed using a conversion algorithm ATR correction on the transmission spectrum based on the input data: the angle of incidence of $45^{\circ}$.

\subsubsection{Water content and ion-exchange capacity (IEC)}

Before measuring the water content, a membrane sample $\left(1.5 \times 1.5 \mathrm{~cm}\right.$, three times) was vacuum-dried at $50^{\circ} \mathrm{C}$ until the constant weight was obtained. Then the membrane was left to swell in demineralised water for 12 hours and after wiping the free water with filter paper rapidly and carefully, the membrane was weighed immediately.

After conditioning in $\mathrm{Cl}^{-}$cycles, IEC of an IEM was determined in the following manner: $1 \mathrm{~g}$ of the membrane sample was treated with $50 \mathrm{~mL}$ of $4 \% \mathrm{NaNO}_{3}$ then the sample was left on a shaker for 1 hour at room temperature. Thereafter, for the actual determination, $10 \mathrm{~mL}$ of the solution was pipetted and diluted to $30 \mathrm{~mL}$ with demineralized water and the sample was titrated with $0.1 \mathrm{M} \mathrm{AgNO}_{3}$ and the equivalence point was determined using $\mathrm{K}_{2} \mathrm{CrO}_{4}$ indicator. IEC of the IEM per gram of dry matter was calculated using the relation (1):

$$
I E C=\frac{\left(\frac{C_{A G N O 3} \times V_{A G N O 3}}{V_{N A N O 3}^{I}}\right) \times V_{N A N O 3}}{M}
$$

where $\mathrm{V}_{\mathrm{AgNO} 3}$ is the volume of $\mathrm{AgNO}_{3}$ solution, $\mathrm{c}_{\mathrm{AgNO} 3}$ is the concentration of $\mathrm{AgNO}_{3}$ solution, $\mathrm{VI}_{\mathrm{NaNO} 3}$ is the consumed amount of the solution for titration $(10 \mathrm{~mL}), \mathrm{V}_{\mathrm{NaNO} 3}$ is the added amount of $0.1 \mathrm{M} \mathrm{NaNO}_{3}(50 \mathrm{~mL})$ and $\mathrm{m}$ is the weight of dried membrane sample.

The IEC has always been done three times and an average was made from the results.

\subsubsection{Electrical resistance and permselectivity}

The electrical resistance is practically important due to its relation with energy consumption in the process. Before the measurement of the specific resistance $\left(\mathrm{R}_{s}\right)$ and the areal resistance $\left(\mathrm{R}_{A}\right)$ of a membrane, a membrane sample $(1.5 \times 1.5 \mathrm{~cm})$ was equilibrated in a solution of $0.5 \mathrm{M} \mathrm{NaCl}$ for 24 hours. The resistance was measured at room temperature in $0.5 \mathrm{M} \mathrm{NaCl}$ in the test cell using a compensation method. The test cell consisted of two parts which are separated from one another by the IEM sample. Constant direct current of $10 \mathrm{~mA}$ was set between interposed platinum electrodes and voltage was measured between reference calomel electrodes at $25{ }^{\circ} \mathrm{C}$. The specific resistance was determined according to the relationship (2):
$R s=\frac{\left(U_{I M+s o l}-U_{s o l}\right)}{I} \cdot \frac{S}{t h}$

where $R_{s}$ is the specific resistance of IEM, $U_{I M+s o l}$ is the potential of a solution with the embedded IEM sample, $U_{\text {sol }}$ is the potential of a solution without inserting IEM sample, I is the direct current, $S$ is the active area of IEM sample of $0.785 \mathrm{~cm}^{2}$ and $t_{h}$ is the thickness of IEM sample.

The areal resistance was determined using the relationships:

$R_{A}=\left(R_{I}^{r+r}-R^{r}\right) A$

$R r=\frac{\left|U_{\text {meas }}(1,2)-U_{a s}^{r}(2,2)\right|_{j}\left|U_{\text {meas }}(2,1)-U_{a s}^{r}(2,1)\right|_{j}}{2 I}$

where $U_{a s}$ is the asymetric voltage and $U_{\text {meas }}$ is the measured voltage. Resistances of samples were measured three times. The results were averaged.

The permselectivity $(P)$ was determined using method of Henderson [22]. Membrane samples $(1.5 \times 1.5 \mathrm{~cm})$ were equilibrated in $0.5 \mathrm{M} \mathrm{KCl}$ for 24 hours before the measurement. 0.1 and $0.5 \mathrm{M} \mathrm{KCl}$ solution were poured into separate parts of the test cell. Permselectivity was subsequently determined according to the relationship (5):

$P=\frac{U_{\text {meas }}}{U_{\text {teor }}} \times 100(\%)$

where $U_{\text {meas }}$ is the measured voltage and $U_{\text {teor }}$ is the theoretical voltage based on Nernst's law expressed by the relationship (6), with regard to the activity of cations $a_{K 1}$, $a_{K 2}$ and anions $a_{A 1}, a_{A 2}$ in $\mathrm{KCl}$ solution present in separate parts of the test.

$$
U_{\text {teor }}=-\frac{R T}{2 F} \times \operatorname{In} \frac{a_{K 1} \times a_{A 1}}{a_{K 2} \times a_{A 2}}
$$

where $\mathrm{R}$ is the universal gas constant $=8.3145 \mathrm{~J} / \mathrm{mol} \mathrm{K}$, $T$ is temperature $(\mathrm{K})$ and $F$ is the Faraday constant $=$ $96485 \mathrm{C} \mathrm{mol}^{-1}$. Permselectivity of samples were measured three times. The results were averaged.

\section{Results and discussion}

\subsection{Surface modification}

The commercially available PES membrane was surface-modified with monomers. This surface modification resulted in a two layers membrane containing a PES layer and a layer of poly (styrene-co-divinylbenzene-co-4-vinylbenzyl chloride). 

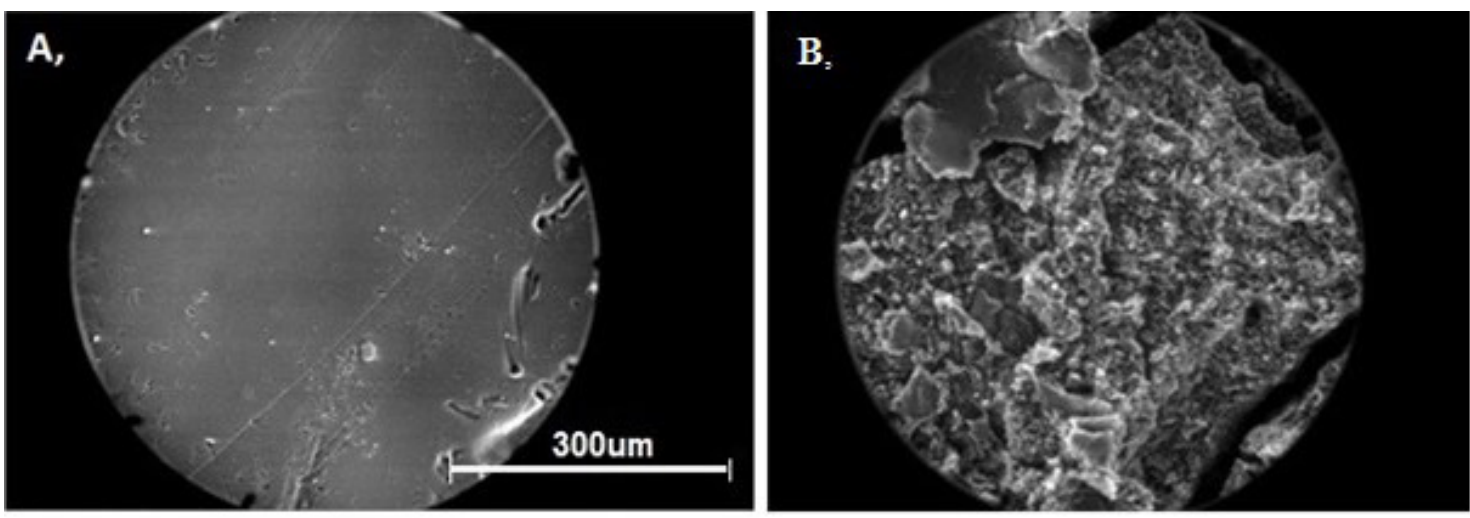

Fig. 2 The SEM surface images (500x magnification): A - PES membrane without modification and extraction treatment, B - AEM coated with surface layer after the extraction in THF.

Surface modification aims to improve the ionic properties and electrochemical properties of the membrane. To remove unreacted compounds and to tailor the porosity and surface morphology of the grafted copolymer separation layer, the extraction of surface modified two-layer membranes was carried out using solvent THF. The effect of extraction treatment surface morphology is shown in Fig. 2. It is evident that the surface of the membrane was changed by extraction. The two-layer membrane treated particularly by THF extraction may provide favorable ionic conducting performance with improved electrochemical characteristics and decreased impact on the polarization phenomenon.

The prepared membranes were stored in deionized water at room temperature for 1.5 years. The membrane sample was re-characterized after 1.5 year to determine stability with respect to the determination of surface morphology. From Fig. 3, it can be observed that morphological changes have not occurred with the elapsed time 1.5 year.

FT-IR spectroscopy was carried out for comparing the PES membrane without modification, the AEM and the AEM after 1.5 year (see Fig. 4). The peaks assigned to aromatic groups were shown at $1630 \mathrm{~cm}^{-1}$ and $1490 \mathrm{~cm}^{-1}$ and those of quaternary ammonium group at 980, 898 and $812 \mathrm{~cm}^{-1}$. It is evident from the curve corresponding to the AEM that the surface layer containing ion-exchange amino functionalities was covalently grafted on the support PES membrane even after performing THF extraction.

The sample was re-measured after 1.5 year to verify morphology using FT-IR spectroscopy. From Fig. 4 can be observed comparable FT-IR spectrum as with the sample after preparation. From this fact it can be concluded that there has been no drastic changes in the surface modification after 1.5 year.

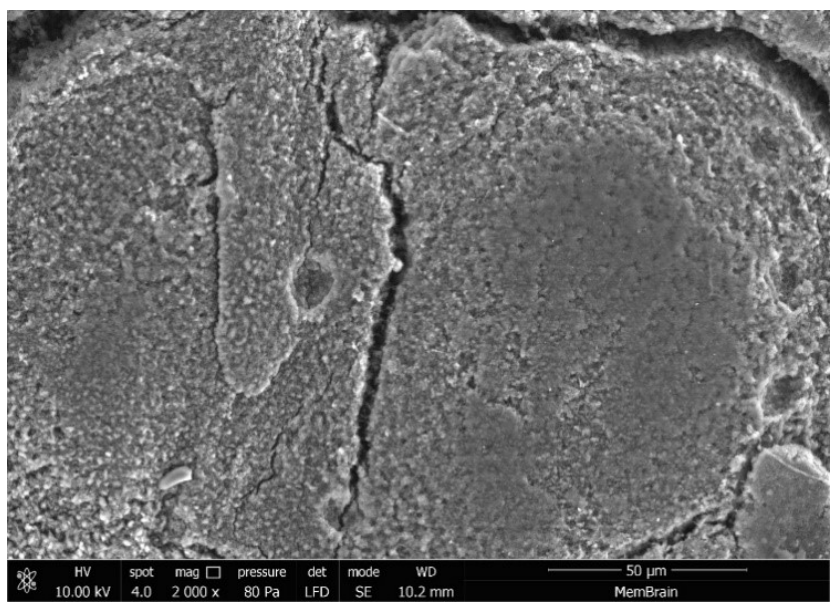

Fig. 3 FT-IR spectra of PES membrane without modification, surface modified PES membrane with amino groups after 1.5 year.

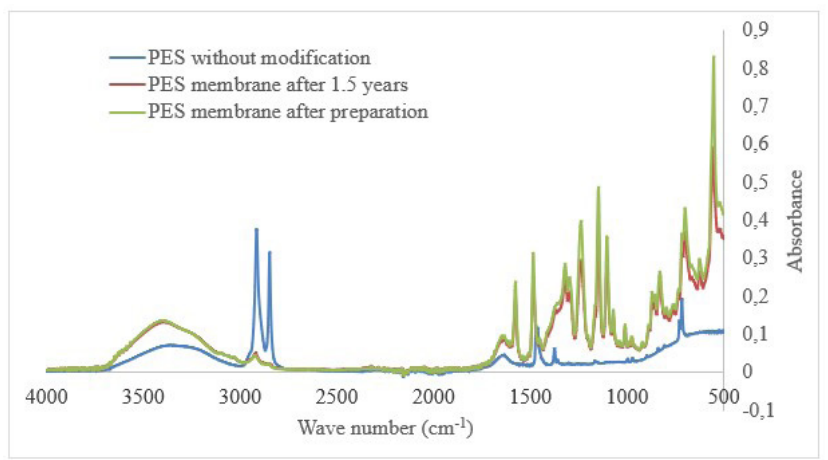

Fig. 4 The SEM surface images (2000x magnification) of AEM coated with surface layer after the extraction in THF after 1.5 years.

\subsection{Water content and electro-chemical properties}

Determination of water content is of great importance in terms of applicability of the ion-exchange resin. Water assists the transportation of ions from the anode to the cathode. Hence, IEMs should absorb sufficient water, 
whereas excessive water absorption will induce the loss of dimensional stability and mechanical properties. With a higher water content value, increased conductivity can be expected, which is connected with higher affinity to ions. The prepared modification PES membrane after extracted with THF had water content 5.1 wt. \%.

To evaluate the functionality of AEMs, IEC was chosen as an evaluative property. The ion-exchange capacity refers to a number of ions that the system is able to bind and it is known to have the profound effects on many important properties of ion-exchange membranes. The membrane sample had IEC $1.3 \mathrm{meq} / \mathrm{g}$ dry matter.

The electric resistance for surface modified PES membranes without amination and for AEMs (after introducing functional amino groups) was examined (see Table 2). It was shown that all surface modified two-layer membrane without amination exhibited extremely high values of AVG areal and specific resistance $\left(R_{A}\right.$ and $\left.R_{S}\right)$ in contrast to AEMs, which indicates that the porous PES support layer (exhibiting relatively low electric resistance owing to the porous character) was sufficiently coated with a compact insulating polymer surface layer. After introducing polar amino functionalities, the conductivity of the two-layer modified membranes increased significantly. According to results of electric resistance, the most convenient electric properties were found for the surface modified AEMs coated with the surface layer 2 and treated with THF extraction. The improved electric properties are probably connected both by the porous character and the increased mobility of the covalently grafted surface layer copolymer (due to lower network density), both phenomena leading to improved ion transport. The AVG results are from the third measurement with standard deviation $0.02 \Omega . \mathrm{cm}^{2}$ for $\mathrm{R}_{\mathrm{A}}$ and $0.5 \Omega . \mathrm{cm}$ for $\mathrm{R}_{\mathrm{S}}$.

Permselectivity for the two-layer AEMs was investigated as well. Permselectivity indicates the proportion of the charge transferred from the counter ions to the total transferred charge. The results of AVG permselectivity with standard deviation $0.4 \%$ we can see in Table 3 . Permselectivity had very good results, after 1.5 year it was $91.1 \%$. The samples were left in deionized water, there was a better swelling of the structure with the case and thus increased permselectivity.
Table 2 Results of AVG specific resistance $\left(R_{A}\right.$ and $\left.R_{S}\right)$ in the time.

\begin{tabular}{lccc}
\hline AEM membrane & $\begin{array}{c}\text { Thickness } \\
(\mu \mathrm{m})\end{array}$ & $\begin{array}{c}\text { AVG } \mathrm{R}_{\mathrm{A}} \\
\left(\Omega . \mathrm{cm}^{2}\right)\end{array}$ & $\begin{array}{c}\mathrm{AVG} \mathrm{R}_{\mathrm{S}} \\
(\Omega . \mathrm{cm})\end{array}$ \\
\hline After production & 386 & 5.20 & 179.0 \\
After 3 months & 291 & 5.20 & 179.0 \\
After 6 months & 286 & 6.10 & 207.0 \\
After 1 year & 269 & 5.50 & 209.0 \\
After 1.5 year & 276 & 6.90 & 248.0 \\
\hline
\end{tabular}

Table 3 Results of permselectivity in the time.

\begin{tabular}{lc}
\hline AEM membrane & AVG Permselectivity (\%) \\
\hline After production & 73.2 \\
After 3 months & 73.2 \\
After 6 months & 96.9 \\
After 1 year & 93.4 \\
After 1.5 year & 91.1 \\
\hline
\end{tabular}

\section{Conclusion}

Two-layer AEM based on a commercial PES microfiltration membrane was successfully prepared by grafting a polymeric surface layer of poly(styrene-co-divinylbenzene-co-4-vinylbenzylchloride) onto the PES membrane support layer.

Thus, the surface layer treatment producing different surface morphology and porosity was shown to play a crucial role in membrane performance and two-layer membranes exhibiting both high permeability and permselectivity, can be successfully prepared by tailoring the surface layer porosity. It was verified that 1.5 years after the modified membrane did not change the morphological and electrochemical properties. These membranes can find application in electrodialysis processes.

\section{Acknowledgement}

The work was carried out within the framework of the project No. LO1418 "Progressive development of Membrane Innovation Centre" supported by the program NPU I Ministry of Education Youth and Sports of the Czech Republic, using the infrastructure Membrane Innovation Centre. Figures can also be in vector format as shown by Fig. 2 and Fig. 3. 


\section{References}

[1] Tanaka, Y. "Ion exchange membranes: fundamentals and applications", Elsevier, Japan, 2015.

[2] $\mathrm{Xu}, \mathrm{T}$. "Ion exchange membranes: state of their development and perspective", Journal of Membrane Science, 263(1), pp. 1-29, 2005. https://doi.org/10.1016/j.memsci.2005.05.002

[3] Strathmann, H. "Membrane Science and Technology Series, 9: Ion Exchange Membrane Separation Processes", 1st ed., Elsevier, San Diego, Ca, USA, 2004.

[4] Davis, T. S. "Electrodialysis", In: Handbook of Industrial Membrane Technology, 1st ed., Noyes Publication, New Jersey, USA, 1990, pp. 40-102.

[5] Strathmann, H. "Ion-exchange membrane separation processes", Vol. 9, 1st ed., Elsevier, 2004.

[6] Li, L., Wang, Y. "Quaternized polyethersulfone Cardo anion exchange membranes for direct methanol alkaline fuel cells", Journal of Membrane Science, 262(1), pp. 1-4, 2005.

https://doi.org/10.1016/j.memsci.2005.07.009

[7] Wang, X.-L., W., Wang, M., Jia, Y.-X., Wang, B.-B. "Surface modification of anion exchange membrane by covalent grafting for imparting permselectivity between specific anions", Electrochimica Acta, 174, pp. 1113-1121, 2015.

https://doi.org/10.1016/j.electacta.2015.06.115

[8] Madaeni, S. S., Amirinejad, S., Amirinejad, M. "Phosphotungstic acid doped poly(vinyl alcohol)/poly(ethersulfone) blend composite membranes for direct methanol fuel cells", Journal of Membrane Science, 380(1-2), pp. 132-137, 2011.

https://doi.org/10.1016/j.memsci.2011.06.038

[9] Pandey, J., Shukla, A. "PVDF supported silica immobilized phosphotungstic acid membrane for DMFC application", Solid State Ionics, 262(1), pp. 811-814, 2014.

https://doi.org/10.1016/j.ssi.2013.10.029
[10] Kim, S.-J., Jones, C. W., Nair, S. "Ion exchange of zeolite membranes by a vacuum 'flow-through' Technique", Microporous and Mesoporous Materials, 203(1), pp. 170-177, 2015. https://doi.org/10.1016/j.micromeso.2014.10.017

[11] Zhong, S., Cui, X., Dou, S., Liu, W. "Preparation and characterization of self-crosslinked organic/inorganic proton exchange membranes", Journal of Power Sources, 195, pp. 3990-3995, 2010. https://doi.org/10.1016/j.jpowsour.2009.12.125

[12] Nagarale, R. K., Gohil, G. S, Shani V. K., Rangarajan, R. "OrganicInorganic Hybrid Membrane: Thermally Stable Cation-Exchange Membrane Prepared by the Sol-Gel Method", Macromolecules, 37(26), pp. 10023-10030, 2004. https://doi.org/10.1021/ma048404p

[13] Li, J.-F., Xu, Z.-L., Yang, H., Yu, L.-Y., Liu, M. "Effect of $\mathrm{TiO}_{2}$ nanoparticles on the surface morphology and performance of microporous PES membrane", Applied Surface Science, 255(9), pp. 4725-4732, 2009.

https://doi.org/10.1016/j.apsusc.2008.07.139

[14] Zinadini, S., Zinatizadeh, A. A., Rahimi, M., Vatanpour, V., Zangeneh, H. "Preparation of a novel antifouling mixed matrix PES membrane by embedding graphene oxide nanoplates", Journal of Membrane Science, 453, pp. 292-301, 2014. https://doi.org/10.1016/j.memsci.2013.10.070

[15] Kang, M.-S., Choi, Y.-J., Choi, I.-J., Yoon, T.-H., Moon, S.-H. "Electrochemical characterization of sulfonated poly (arylene ether sulfone)(S-PES) cation-exchange membranes", Journal of Membrane Science, 216(1), pp. 39-53, 2003. https://doi.org/10.1016/S0376-7388(03)00045-0 